\title{
O desafio da política de atendimento à infância e à adolescência na construção de políticas públicas eqüitativas
}

\author{
The challenge of health care provision \\ for children and adolescents as part \\ of equitable public policies
}

Maria Helena Magalhães de Mendonça ${ }^{1}$

\footnotetext{
1 Núcleo de Estudos Político-Sociais em Saúde, Departamento de Administração e Planejamento em Saúde, Escola Nacional de Saúde Pública, Fundação Oswaldo Cruz. Rua Leopoldo Bulhões 1480 , Rio de Janeiro, $R J$ 21041-210, Brasil. mhelenam@ensp.fiocruz.br
}

\begin{abstract}
The author analyzes the new social policy shaped by the assimilation of the notion of integral social protection with a view towards equity. The premises marked the social reform contained in the wording of the 1988 Constitution and in the laws regulating the respective rights during the 1990s, including public social assistance, health care, and education. The article demonstrates how, in the former context, Brazil's children and adolescents were subject to great vulnerability due to their position in the country's social structure, aggravated by differential access to public goods and services. An analysis of the health care policy for children and adolescents, emphasizing an inter-sectoral approach and redefining social and health programs and measures in the 1990s, was not intended to be conclusive but did point to some trends in the reorganization of public social assistance policy for low-income youth, in keeping with gains obtained in social indicators of vulnerability in the areas of health, education, and labor during the last decade. Still, the author concludes that this policy reorientation renewed the tension between targeting more vulnerable segments of the population with selective measures as compared to universal and comprehensive access to social protection.
\end{abstract}

Key words Child Health; Adolescence; Social Assistance; Health Care; Equity

Resumo O trabalho analisou a nova política social que se configurou pela assimilação da noção de proteção social integral com vistas à eqüidade. Os seus pressupostos marcaram a reforma social contida no texto constitucional de 1988 e nas leis regulamentadoras dos direitos assegurados - assistência social, saúde e educação públicas - nos anos 90. Mostrou-se que, no contexto precedente, a população jovem no Brasil apresentava situação de grande vulnerabilidade, em face da sua posição na estrutura social, reforçada pelo acesso diferenciado a bens e serviços públicos. A análise da política de atendimento para a infância e adolescência, que enfatizou a intersetorialidade e redefiniu os programas e ações sociais e de saúde, nos anos 90, não pretendeu ser conclusiva, mas apontou algumas tendências na reordenação da política de assistência pública para o população jovem pobre, compatíveis com alguns avanços dos indicadores sociais de vulnerabilidade na área da saúde, educação e trabalho na década. Contudo, considerou-se que essa reorientação renovou a tensão entre a focalização nos segmentos mais vulneráveis, com seletividade das ações a serem oferecidas e a universalização com integralidade da proteção social. Palavras-chave Saúde Infantil; Adolescência; Assistência Social; Assistência à Saúde; Eqüidade 


\section{Introdução}

Este trabalho apresenta algumas reflexões, fruto de estudo da trajetória da proteção social à infância e à adolescência no Brasil republicano, que resultou em uma tese de doutoramento, e visa abrir espaço dentro do campo da saúde pública para um estudo mais aprofundado do atendimento ofertado à população nestas fases de desenvolvimento humano. Sua base, portanto, é um estudo retrospectivo, que analisou a estruturação da política de proteção social para entender as tendências observadas no contexto atual.

Os processos de modernização e democratização experimentados no Brasil nas últimas décadas do século XX, permitiram reordenar a política de assistência social para o conjunto da população, estabelecendo novos parâmetros para a intervenção pública. No campo da assistência pública, incorporou-se a redefinição da infância e da adolescência como processos sociais de desenvolvimento humano e se estabeleceu uma dimensão de prioridade à proteção social dirigida aos jovens, pessoas em formação, que exigem atenção específica.

A partir dessa priorização o exame das situações de vulnerabilidade da população jovem no Brasil, que foram sistematizadas no início dos anos 90, identificaram diferentes condições de vida entre os jovens, que resultavam de sua posição na estrutura social combinada a um acesso diferenciado aos serviços e bens de assistência pública.

Assim, reorientar os programas e ações sociais, em especial aqueles que se destinavam à redução da pobreza, situação em que se encontra grande parte da população de jovens, passou a ser uma nova exigência das políticas públicas. A reforma social brasileira nos anos 90 incorporou a noção de proteção integral e universal com eqüidade, seguindo tendência internacional e visando, especialmente, no campo da infância e da adolescência a mudança no processo de integração social dos jovens.

Ao analisar esse processo do ponto de vista formal está se querendo verificar tendências, enfatizar a pertinência do objeto - a proteção social da infância e da adolescência - e apontar para necessidade de mais estudos cujos resultados aprofundem a análise política da proteção social à juventude no país.

\section{A infância e a adolescência nas políticas públicas}

A percepção mais difundida da criança e do adolescente como seres em desenvolvimento no mundo moderno, foi resultado de um longo processo social que envolveu transformações na organização social, desde o ponto de vista da esfera privada das famílias até a esfera pública da conviviabilidade social. A infância e a adolescência entendidas como categorias socialmente construídas, permitiram a adoção de práticas sociais condutoras do processo de formação da identidade sociocultural infanto-juvenil (Ariès, 1981).

Essas práticas foram a assistência, saúde e educação que atingiram seu objetivo e se validaram como opção ao enfrentamento da questão social, na medida de sua publicização e laicização, ou seja, conforme adotaram um caráter universal, obrigatório e de responsabilidade do Estado.

A assistência pública focalizada nos pobres, em qualquer sociedade do mundo ocidental, onde predominou um enfoque antiliberal evoluiu a partir da hipótese de que a pessoa em formação, devidamente assistida, chega à maturidade pelo exercício do direito de se autoaperfeiçoar para, então, gozar de sua cidadania plena ou de um conjunto de direitos que se articulam progressivamente. Esses direitos são apropriados gradativamente pela pessoa em seu processo de desenvolvimento.

Para Therborn (1993), os direitos da infância foram definidos tardiamente e obedeceram a uma lógica inversa à definição dos direitos sociais do homem trabalhador, por não depender exclusivamente da regulação na esfera da produção. A evolução dos direitos sociais coincidiu com o avanço da sociedade de bem-estar que publicizou a educação e a saúde, estabelecendo a universalização e obrigatoriedade da atenção educacional e sanitária aos jovens, como condições mínimas para o desenvolvimento do indivíduo dentro de marcos civilizatórios, além de outras formas de assistência que conferem à família renda e trabalho ou formação para o trabalho, no caso dos jovens.

São recentes as leis de proteção à criança e ao adolescente que instituíram a igualdade entre membros legítimos e ilegítimos de uma família, tendo por base o homem, chefe de família, permitindo que todos os filhos tivessem acesso aos bens familiares. O direito, em caso de litígio, de definir quem oferece melhor condição à criança, também é benefício atual na definição da guarda ou tutela familiar.

As leis que defendem a integridade, criminalizando maus tratos físicos e mentais, seja 
pelos pais e ou pelas instituições de assistência aos jovens (Therborn, 1993), foram adotadas somente nas últimas décadas. Esses direitos, definidos no âmbito do direito civil, pois regularam a propriedade e as relações do indivíduo na esfera privada, têm uma dimensão social associada à liberalização da tutela familiar.

Essa interface definida em lei, deu forma à proteção social integral como paradigma de intervenção estatal pública junto à infância e à adolescência. Tal perspectiva embrionária desde o início do século XX, se materializou em poucos países, que adotaram o regime socialdemocrata no período entre as guerras, estendendo-se progressivamente no pós-guerras para quase toda a Europa.

Em tese, uma proteção social universal e integral, articulada por sistemas públicos de assistência social, educação e saúde públicas, faria parte de um sistema de proteção social mais amplo, que, incluindo certas garantias de renda mínima, visando o bem-estar social da criança dentro das famílias, constituiria um conjunto de direitos formais que o realizariam, eliminando a pobreza (Draibe, 2000).

Esse fenômeno social recente não se consolidou em termos globais no mundo moderno, e onde foi implantado esbarra atualmente no desafio de ampliar as ações preventivas e de integração social num contexto de contenção de gastos públicos. O Estado social em diversos países europeus administra suas dificuldades, experimentado novas estratégias de obtenção de renda, fora do contrato estável de trabalho, combinadas a atividades sociais prestadas pela beneficência ou pelo voluntariado, em serviços próprios ou apoiados no serviço público, que vêm se reorganizando segundo uma nova legitimidade (Castel, 1995; Gorz, 1994; Habermas, 1997; Rosanvallon, 1995).

A proposta de proteção integral à criança e ao adolescente foi retomada pela Convenção da Organização das Nações Unidas (ONU), nos anos 90, a partir do diagnóstico de que o processo de exclusão do jovem já chegou a limites indesejáveis, indicando a necessidade de oferecer às futuras gerações novas condições de existência e desenvolvimento. Para além das desigualdades regionais, a ONU busca apontar uma dimensão universal para a integração dos jovens.

O Brasil é signatário dessa convenção, que repercutiu na reorientação da política que se analisará (IPEA/UNICEF/IPLAN, 1990; ONU/ UNICEF, 1990).

\section{A infância e a adolescência entre os pobres no Brasil}

No Brasil, a construção histórica da questão da assistência a jovens pobres passou por alguns momentos: a promulgação do Código de Menores de 1927 que configurou este campo de intervenção; a consolidação da organização da assistência social fragmentada entre o atendimento aos menores e outras iniciativas de proteção social para o atendimento da criança, na área do trabalho, na normatização de ações preventivas de saúde e assistência social e na obrigatoriedade do ensino fundamental no período entre 1930 e 1943; a vigência da Política de Bem-Estar do Menor (PNBEM), entre 1964 e 1988, com a criação da Fundação do Bem-Estar do Menor (FUNABEM); e a formulação e a implantação do Estatuto da Criança e do Adolescente (ECA), nos anos 90, que consolidou novas formas de trabalhar com os jovens, já experimentadas na sociedade por diferentes Organizações Não Governamentais (ONGs), especialmente na área educacional e de formação para o trabalho (Alvim, 1994; Rizzini, 1995; Vogel, 1995).

A redemocratização dos anos 80 implicou na redefinição das políticas sociais que reordenaram o sistema de proteção social a partir de princípios como descentralização, participação social e a universalização da atenção, visando reduzir a exclusão social e garantir a eqüidade, no plano dos direitos.

Neste sentido, a política de assistência social na Carta de 88 se integrou ao Sistema de Seguridade Social, definindo-se como um conjunto integrado de ações de iniciativa pública e da sociedade civil, que se voltariam para a proteção à família, à maternidade, à infância, à adolescência, à velhice; o amparo às crianças e adolescentes carentes; a integração dos jovens no mercado de trabalho; a habilitação, reabilitação e integração de pessoas portadoras de deficiência.

A política social implícita no ECA, definiu que a ação social das novas agências devia superar as condições materiais e oferecer novos estilos ou comportamentos e atitudes que emancipassem o jovem, percebido como sujeito de direitos.

A nova política se caracterizou pela modificação da tutela jurídica, substituída pelo compromisso do Estado em oferecer assistência integral, pública, gratuita e universal ao jovem segundo as necessidades de cada fase de seu ciclo de desenvolvimento.

A modernização dos processos da infância e da adolescência no Brasil visou também a re- 
construção da imagem da família brasileira, devolvendo-lhe a responsabilidade de criar e educar seus filhos, a partir de suas condições materiais. Assim, prioritariamente a criança deve permanecer junto aos pais, exigindo que as políticas foquem o ambiente social onde se inserem crianças e adolescentes, para atender à necessidade do grupo familiar. A política de atendimento passa a ser centrada não só no indivíduo mas no alcance de suas relações sociais, sejam os demais membros familiares, sejam as comunidades onde eles vivem (Mendonça, 2000).

Essas novas definições esbarraram em alguns constrangimentos nos primeiros anos da década de 90 . O setor social de assistência foi desmontado pelas reformas liberais implementadas, sem que se definissem novos programas e ações que abordassem as desigualdades sociais dado à vulnerabilidade dos jovens brasileiros no âmbito local.

A situação de indigência desse grupo social, no Brasil, divulgada pelo governo (IPEA/IPLAN, 1993), já no período pós-impeachment do Presidente Fernando Collor, apontava para sua distribuição espacial, para a configuração familiar das crianças e adolescentes indigentes e para o grau de participação dos jovens de 7 a 14 anos nas instituições sociais - escola e trabalho - e permitiu estabelecer os parâmetros da focalização das políticas que poderiam ser adotadas.

A revisão dessas relações sociais se apoiou, sem dúvida, na discriminação dos grupos por faixas etárias ligadas aos principais ciclos de vida, em face da percepção de diferentes necessidades e da exigência de diferentes formas de ação durante o processo de desenvolvimento individual e social: a primeira infância (pré-escolaridade), a infância (escolarização) e adolescência (escolarização mais capacitação profissional).

O contingente de miseráveis na população total brasileira estava em 1990 na ordem de 32 milhões, entre os quais 15 milhões eram crianças e jovens entre zero e 18 anos (IPEA/IPLAN, 1993). Portanto, a incidência de jovens em situação de indigência correspondia a cerca de $25 \%$ da população infanto-juvenil, que era de 45 milhões.

A indigência infanto-juvenil como um fenômeno urbano, se destacava nas áreas metropolitanas e nas maiores concentrações como o Rio de Janeiro (471 mil) e em São Paulo (327 mil) na Região Sudeste, seguidos por Recife (283 mil) e Fortaleza (229 mil) na Região Nordeste.

Os índices de indigência se reduziam com o aumento da idade das crianças, o que pode estar associado a uma capacidade de gerar rendimentos por parte dos diversos membros da fa- mília, incluindo os próprios adolescentes. É entre a população de zero a 6 anos que se encontravam as maiores ocorrências da condição de indigência, sendo sempre mais intensa na Região Nordeste do país.

A dimensão rural do fenômeno chama a atenção para a estrutura familiar sendo maior na faixa de zero a seis anos, e na condição de membro de família estruturada de modo monoparental, com chefia feminina que participa do mercado de trabalho.

A chefia feminina apareceu proporcionalmente maior entre os adolescentes de 15 a 17 anos, indicando que a ruptura do vínculo conjugal e o isolamento da mulher podem estar associados às dificuldades de garantir a reprodução da prole, colocando-a no circuito do mercado de trabalho.

O abandono escolar entre a população indigente infanto-juvenil total era bastante elevado - 1,6 milhões (26\%) de crianças na faixa de idade com freqüência escolar obrigatória, estavam fora da escola, sendo maior a proporção de crianças indigentes sem freqüentar escola no meio rural e nas regiões metropolitanas.

A proporção de jovens que não freqüentavam a escola alcançava $60 \%$ entre os jovens de 15 a 17 anos. Essa situação variava bastante conforme a condição de domicílio, sendo sempre mais grave no meio rural. Entre os jovens de 15 a 17 anos, $23 \%$ eram analfabetos e $20 \%$ tinha ensino básico (quatro primeiras séries) concluído.

Essa baixa escolaridade somada a não freqüência à escola repercute nas condições de inserção no mercado de trabalho e de superação da pobreza, agravada pela precocidade em que este grupo ingressa no mercado para complementar a renda familiar ou buscar seu próprio sustento. A condição de trabalho era mais freqüente no meio rural, onde estavam maiores taxas de ocupação para essa faixa etária.

Isto constitui uma situação desfavorável, em especial para as crianças, pela deterioração do trabalho infantil, com baixíssima remuneração, associada à família como unidade econômica produtora neste setor e até ao trabalho escravo.

Ao analisar a participação do jovem entre 10 e 14 anos no mercado de trabalho, e a relação entre a freqüência à escola e a apartação dessa etapa de socialização, observou-se que a situação dos jovens entre os 10 e 14 anos estava longe de garantir condições de desenvolvimento integral aos mesmos.

Estudos mais recentes atualizam essa realidade permitindo observar onde e como o desenvolvimento humano se expressou com maior 
sensibilidade, atuando sobre os fenômenos de vulnerabilidade crescentes no período de 1970 a 1990. Assim, alguns indicadores medidos no intervalo entre os anos de 1992 e 1999 apresentaram uma pequena queda (IBGE, 2000).

O setor saúde contribui para este quadro com os indicadores de saúde e longevidade esperança de vida ao nascer e taxa de mortalidade infantil - que vêm mostrando uma contínua e progressiva melhora nestas duas décadas, associada aos investimentos realizados na infra-estrutura de serviços de saúde e saneamento e ao aumento da cobertura. Ao longo dos anos 90, aprofundou-se a definição mais precisa de programas de saúde para a população total e para grupos específicos como a mulher, a criança e o adolescente, entre outros, que inclusive adotaram uma perspectiva mais coletiva e preventiva.

No entanto é ainda na área de saúde que se observam indicadores que expressam fortemente os riscos que afetam a população jovem entre 15 e 19 anos, como a taxa de mortalidade proporcional por causas de óbitos. Para o Brasil temos que em 1992, 63\% dos óbitos entre jovens eram por causas externas, sendo a menor taxa da Região Norte (52\%), enquanto no Sudeste (69\%) ultrapassou a média nacional. Em 1999, esses percentuais continuam a crescer sendo a taxa para o Brasil de $68 \%$, enquanto o Sudeste tem $73 \%$ e a Região Norte $62 \%$ (IBGE, 2000).

Evidencia-se também que a taxa de atividade total entre os jovens teve pequena variação entre 1992 (61,5\%) e 1999 (61,0\%). No entanto, é significativa a queda para o grupo de 10 a 14 anos, de 22\% em 1992 chega a 17\% em 1999. Para o grupo de 15 a 17 anos, a variação é de $54 \%$, em 1992, para 45\% em 1999. Essa variação se dá em todas as unidades da federação e nas regiões metropolitanas (IBGE, 2000).

A queda no emprego das crianças e adolescentes pode indicar a redução da incorporação precoce dos jovens, contudo os maiores de 18 esbarram com poucas oportunidades de absorção no mercado de trabalho, qualquer que seja sua qualificação profissional. Isto se agrava nas camadas populares com baixa escolaridade e sem especialização técnica, indicando uma tendência de exclusão dessa população.

A taxa de escolarização apresenta uma elevação em todas as faixas de idade que compõem tradicionalmente a população de estudantes. Esse aumento se dá especialmente entre crianças de 5 e 6 anos, mostrando em 1999 maior freqüência à pré-escola $(71 \%)$, que em 1992 (54\%). Para a faixa de 7 a 14 anos observase que $87 \%$ freqüentavam a escola em 1992, taxa que sobe para $96 \%$ em 1999. Para os adoles- centes entre 15 e 17 anos tem-se $60 \%$ de freqüência em 1992, passando-se a 78,5\% em 1999.

A análise preliminar destes dados apontaram algum impacto da vigência de normas legais que exigem a presença obrigatória na escola do jovem até 14 anos; proíbem o trabalho infantil e inibem a incorporação precoce do jovem entre 12 e 14 anos, fase em que ele pode ser apenas sujeito de treinamento, estando excluído do mercado formal.

Mesmo reduzidos o trabalho infanto-juvenil e a não escolarização em seus distintos e negativos aspectos - evasão, baixa escolaridade e analfabetismo - se somam à falta de capacitação profissional para compor a problemática enfrentada por essa população, também marcada pela fome e desnutrição, que prejudicam sua saúde, além da violência, que afeta sua existência.

Os riscos inerentes a estas precárias condições de vida caracterizadas pela fragilidade do núcleo familiar e fracasso da escola como agentes socializadores de base, e pelas vivências de rua, se traduzem em muitas situações de risco para a infância e a juventude, que são formas de exploração que as sociedades desenvolvidas já conseguiram controlar, e que permanecem como desafios para a política de atendimento à juventude no Brasil.

A exclusão que se observa ainda pressiona os jovens a formas negativas de integração, levando alguns até mesmo a carreira de infrator, onde esbarram com a marginalização jurídicopolicial. Esta mais ainda faz parte de um processo político que tem como efeito reforçar a exclusão do processo decisório, que ordena a vida social, política e econômica e a sua não integração social (Luz, 1993).

\section{A política de atendimento à infância e à adolescência}

O governo que tomou posse, em 1995, estruturou sua política no campo social privilegiando o planejamento em torno das ações sociais básicas, e se propondo a organizar a sociedade civil para a ação substitutiva ao Estado na esfera social, em especial, quanto à política sanitária, à erradicação do analfabetismo e à formação do jovem para o trabalho.

Duas foram as vertentes das políticas do governo federal voltadas para a juventude, visando alterar o quadro já descrito. Uma foi a Política de Promoção e Proteção Integral da Infância e da Adolescência, apresentada desde 1995, pelo Ministério da Justiça, simultaneamente ao desmonte das estruturas herdadas da Política Nacional de Bem-Estar do Menor, já al- 
teradas na gestão no primeiro governo democrático pós-constituinte.

Esta se definiu pelo propósito de focalizar nas situações, ditas especiais, de erradicação do trabalho infantil e de controle das formas de violência e prevenção do uso de drogas por medidas socioeducativas. Além de fomentar a implementação dos Conselhos e Fundos de Defesa dos Direitos descentralizados. Este, apesar de sua relevância para a problemática não foi o alvo especial deste trabalho, valendo apenas destacar que os recursos administrados pelo Conselho e Fundo de Defesa da Criança e Adolescente se destinavam à proteção especial, e preservaram o caráter residual da política de assistência da PNBEM, sem ingerência nos recursos setoriais da política social básica.

Outra vertente foi o Programa Comunidade Solidária que se dirigiu prioritariamente ao jovem, indigente e vulnerável a situações de risco social, por meio de uma série de programas setoriais com ênfase em saúde, educação, geração de renda e trabalho.

As duas vertentes da política de atendimento apontadas, partiam do pressuposto que sua intervenção devia ser focalizada e que as ações objetivavam reverter situações especiais ou de risco social, que afetavam a população-alvo. As ações eram definidas como homogêneas, não considerando diferenças entre os diversos grupos ou reações em face das intervenções. O que as diferenciava era o locus onde elas ocorriam e os agentes que as deslanchavam (Volpi, 1999).

O Comunidade Solidária colocou-se como um programa articulador e promotor de integração institucional e de intersetorialidade. Buscava unificar os recursos públicos na área de assistência pública, focando as populações de áreas territoriais mais necessitadas socialmente. A prioridade era expandir as ações sociais para áreas não cobertas nos estados e municípios, e por mecanismos que não implicassem aumentos futuros nos gastos governamentais, que se denominou formalmente de parcerias (Mendonça, 2000).

Na Agenda Básica do Comunidade Solidária constava a implementação de "programas inovadores", desenvolvidos em parceria com entidades privadas e que passariam a ser referências para políticas públicas, especialmente na área da educação de jovens, destacando-se os Programas de Alfabetização Solidária, Capacitação de Jovens e Universidade Solidária, que vêm sendo testados como projetos-piloto, avaliados e aperfeiçoados, a fim de serem progressivamente ampliados.

O campo institucional se ampliou mesmo que de forma fragmentada. Surgiram aí novos mecanismos de proteção como bolsa-escola, bolsa-alimentação, que reproduzem as experiências realizadas no plano municipal, no processo mais geral de responsabilização do Estado, e que reconhecidamente não têm alcançado seu objetivo de inserir no mercado de trabalho, as famílias pobres pelo constrangimento imposto aos investimentos econômicos, embora melhorem as condições de vida pelo consumo de diversas mercadorias.

Ao servirem de alívio ao sofrimento das famílias, aumentando sua baixa renda, reforçando o trabalho doméstico (não remunerado) das mulheres chefes de família, oferecendo recursos sociais e mantendo os jovens na escola, com melhor rendimento, responderam talvez, embora não se tenha avaliação mais apurada, por uma renovação na solidariedade/reciprocidade dentro do núcleo familiar de baixa renda, pensado como grupo social, e mesmo na comunidade onde essa forma de sociabilidade é mais espontânea.

O trabalho com a comunidade, ao melhorar as condições de vida local, deram margem à abertura de espaços para fora, ampliando os níveis de solidariedade social e as condições de viabilização da democracia, por ampliar a participação presente e futura.

No caso da saúde da criança e do adolescente se priorizou todo um conjunto de ações básicas de saúde, com base nos princípios da integralidade e universalidade, já definidos no âmbito da saúde pública desde os anos 80 . No novo contexto, essa atenção se voltava para grupos de risco, em sua intercessão com critérios seletivos definidores de pobreza e indigência. Contudo, preservava seu objetivo maior de assegurar as condições necessárias à manutenção e reprodução da vida humana saudável.

O Comunidade Solidária definiu sua intervenção no cuidado com a saúde no âmbito do Programa Saúde da Família (PSF), em sua fase inicial em que se privilegiava a implantação em áreas de maior risco social. Essa intervenção indicou um caráter emergencial das ações e foi realizada a partir de novas práticas e profissionais de saúde que compuseram a equipe da Saúde da Família.

O PSF contém em sua essência características como: ênfase na atenção à família e não apenas ao indivíduo; visão ativa de intervenção em saúde, buscando-se agir sobre a mesma preventivamente e organizando a demanda; integração com a comunidade e enfoque multiprofissional e interdisciplinar (Levcovitz \& Garrido, 1996). Este último era fundamental para construção de conhecimento sobre os grupos prioritários, especialmente no caso do jovem. 
Nessas práticas destacaram-se as atividades de promoção social e de educação em saúde, segundo um agravo ou uma dada problematização, a partir de trabalho de campo junto à comunidade e à população cadastrada, classificada por critérios etários ou de agravos.

Para crianças se acionou os princípios já difundidos e exitosos dos programas de atenção integral à criança e à mulher em sua fase reprodutiva. No caso do adolescente, cuja procura por atenção restringe-se a constatação de algum mal-estar súbito quase sempre ainda mediado pela família ou pela escola, deu-se ênfase às ações apontadas pelo Programa de Saúde do Adolescente (PROSAD), que não visam o adoecimento e sim tratar temas que podem promover a saúde dos jovens, prevenir riscos e engajá-los na luta por sua cidadania.

As ações básicas reunidas no PROSAD cobrem crescimento e desenvolvimento, sexualidade e saúde reprodutiva, saúde mental, prevenção de acidentes, violência, maus tratos pela família e instituições, já desenvolvidas nos serviços de saúde tradicionais, sendo estimulada a sua realização fora das unidades de saúde, em parceria com outras instituições de assistência e na comunidade.

Na esfera da vida privada, os programas de assistência médico-social, voltados para o jovem, objetivam principalmente prevenir novos problemas que interferem no processo de integração como o uso abusivo de drogas e a sexualidade com riscos. Essas intervenções mudaram a direcionalidade das práticas sociais anteriores, estimuladoras da autonomia, e dão legitimidade e eficácia à promoção da adesão em oposição à resistência, ou seja de um maior controle sobre o cotidiano dos jovens.

Esse paradoxo é problema que, de fato, foi reforçado pelo aumento da expectativa de vida, pelo envelhecimento da população, que estendeu a existência para além do que se convencionou como vida ativa, seja produtiva ou de criação dos filhos, o que tanto pode aumentar as frustrações individuais como exige também a busca de novas escolhas de renovação do acordo social entre homens, mulheres e suas diversas gerações.

Hoje, a liberação das relações homem-mulher, pais-filhos esbarra principalmente na luta contra o desemprego em geral e, em especial, juvenil, podendo-se observar um recuo tático através de medidas sociais que mantêm os jovens afastados do mercado de trabalho por mais tempo, ou incluindo-os simbolicamente em programas que combinam renda mínima e consumo de serviços sociais.

Essas novas estratégias destacam, de toda forma, a existência de duas instituições básicas no processo de reprodução social e cultural dos jovens, que já se observara para a consolidação da infância: a escola e a família, às quais cada vez mais se agregam outras instituiçõos face as transformações nelas ocorridas.

No momento em que o PSF, como estratégia de reorganização dos sistemas de saúde, se expande para os grandes centros urbanos é importante observar em que medida sua forma de atendimento atinge esse segmento social em suas complexas necessidades.

Os problemas que afetam os jovens parecem muito mais complexos do que a estratégia da Saúde da Família possa indicar, embora uma aproximação talvez possa garantir a eficácia, eficiência de seu trabalho perante as comunidades facilitando a articulação com órgãos e instituições não setoriais, ampliando seu leque de intervenções e melhorando seu desempenho.

Os jovens urbanos têm tido seus laços de dependência familiar (econômica e afetiva) estendidos, ao mesmo tempo que sua cultura juvenil os coloca em uma série de conflitos com outras gerações que convivem no mesmo domicílio. Conflitos que são mais intensos quando percebem algum controle sobre sua mobilidade, daí a relevância da ação se estender ao meio social onde vivem.

\section{Considerações finais}

A modernização no campo social se instaurou por um processo gradativo de intervenção nas relações sociais dirigido à transformação da pessoa em indivíduo, ou seja, à construção de identidades, que se inicia nas famílias e foi assumido pelo Estado, especialmente frente às classes populares. Portanto, a modernização repercutiu de imediato na categoria família, provocando sua renovação.

A incorporação do enfoque de desenvolvimento social na reforma social brasileira, que se consolidou nos debates constituintes dos anos 80 , permitiu tratar os problemas da infância e adolescência como fenômenos sociais decorrentes do contexto onde se inserem.

A exigência de inclusão da política de assistência social na agenda das políticas públicas, visando a uma intervenção nos grupos de risco social em seu próprio ambiente, família e comunidade, rompeu com a perspectiva de assistência meramente individualizada, indicando uma intenção de alargar o alvo a ser atingido no processo de desenvolvimento social.

Esse desenvolvimento que deveria desembocar em uma nova política de assistência so- 
cial no contexto da seguridade social se frustrou na década de 90. Assim temos que:

- Os benefícios materiais ofertados aos jovens e às famílias, voltados para sua inserção autônoma no mercado, frente aos limites impostos ao crescimento econômico e ao aumento do desemprego na reestruturação produtiva desencadeada nos anos 80 , ainda são residuais; - A garantia do acesso dos jovens a serviços sociais, promovendo e acompanhando seu desenvolvimento, ainda não é universal, tendo-se mesmo nesta década reforçado sua focalização.

\section{Referências}

ARIÈS, P., 1981. História Social da Criança e da Família. Rio de Janeiro: Guanabara.

ALVIM, R., 1994. Infância das classes populares: A constituição da infância como problema social no Brasil. In: O Trabalhador Carioca. Estudos sobre os Trabalhadores Urbanos do Estado do Rio de Janeiro (A. P. Abreu \& E. Pessanha, org.), pp. 159169, Rio de Janeiro: Editora CJ.

CASTEL, R., 1995. Les Métamorphoses de la Question Sociale. Paris: Libraire A. Fayard.

DRAIBE, S. M., 2000. Por um reforço à proteção à família: Contribuição à reforma dos programas de assistência social no Brasil. In: Família Brasileira: A Base de Tudo (S. Kaloustian, org.), pp. 109-130, 4a Ed., São Paulo: Editora Cortez.

GORZ, A., 1994. Revenue Minimum et Citoyenneté. Droit au Travail vs. au Revenu. Paris: Revue Futuribles.

HABERMAS, J., 1987. A nova intransparência. Novos Estudos CEBRAP, 18:103-114.

IBGE (Fundação Instituto Brasileiro de Geografia e Estatística)/MPOG (Ministério do Planejamento, Orçamento e Gestão), 2000. Síntese de Indicadores Sociais 2000. Série Estudos e Pesquisas, Informação Demográfica e Socioeconômica 5. Rio de Janeiro: IBGE.

IPEA (Instituto de Pesquisa Econômica Aplicada)/ IPLAN, 1993. O Mapa da Criança: A Indigência entre as Crianças e os Adolescentes. Documentos de Política 19. Brasília: IPEA.

IPEA (Instituto de Pesquisa Econômica Aplicada) / UNICEF (Fundo das Nações Unidas para a Infância)/IPLAN, 1990. A Criança no Brasil: O que Fazer? Série Acompanhamento de Políticas Públicas 23. Brasília: IPEA/IPLAN.

LUZ, M., 1993. Relações entre Adolescente e a Sociedade Atual: Instituições, Violência e Disciplina. Série Estudos em Saúde Coletiva 48. Rio de Janeiro: Instituto de Medicina Social, Universidade do Estado do Rio de Janeiro.

MENDONÇA, M. H. M., 2000. Crianças e Adolescentes Pobres de Direitos. A Trajetória da Política Social Dirigida à Infância e Adolescência no Brasil Republicano. Tese de Doutorado, Rio de Janeiro: Instituto de Medicina Social, Universidade do Estado do Rio de Janeiro.
O desafio que fica para as agências que executam a política de atendimento é expandir formas alternativas e mais democráticas de agir, que reforcem mais os vínculos institucionais dos jovens e trabalhem a iniciativa do indivíduo, para que ele elabore projetos para seu próprio desenvolvimento, além de valorizar a livre escolha e manifestação da vontade do jovem diante dos efeitos da crise econômica e social, que atinge a todos.

ONU (Organização das Nações Unidas)/UNICEF (Fundo das Nações Unidas para a Infância), 1990. Plano de Ação para Implementação da Declaração Mundial sobre a Sobrevivência: A Proteção e o Desenvolvimento da Criança nos Anos 90. Genebra: UNICEF.

RIZZINI, I., 1995. Meninos desvalidos e meninos transviados: A trajetória da assistência pública até a era de Vargas. In: A Arte de Governar Crianças: A História das Políticas Sociais, da Legislação e da Assistência à Infância no Brasil (F. Pilotti \& I. Rizzini, org.), pp. 243-298, Rio de Janeiro: Instituto Interamericano del Niño/Editora Universitária Santa Úrsula/Amais Livraria e Editora.

ROSANVALLON, P., 1995. La Nueva Cuestión Social. Repensar o Estado Providencia. Buenos Aires: Ediciones Manantial.

THERBORN, G., 1993. The rights of children since the constitution of modern childhood. A comparative study of Western nations. In: Social Exchange and Welfare Development (L. Moreno, ed.), pp. 67-121, Madrid: Consejo Superior de Investigaciones Científicas.

VOGEL, A., 1995. Do estado ao estatuto: Propostas e vicissitudes da política de atendimento à infância e à adolescência no Brasil contemporâneo. In: $A$ Arte de Governar Crianças: A História das Políticas Sociais, da Legislação e da Assistência à Infância no Brasil (F. Pilotti \& I. Rizzini, org.), pp. 299346, Rio de Janeiro: Instituto Interamericano del Niño/Editora Universitária Santa Úrsula/Amais Livraria e Editora.

VOLPI, M., 1999. A ação do governo federal na defesa dos direitos da criança e do adolescente. In: Políticas Públicas Sociais. Um Novo Olhar sobre o Orçamento da União, 1995/98 (P. E. Rocha, org.), pp. 131-143, Brasília: Instituto de Estudos Socioeconômicos.

Recebido em 2 de maio de 2002

Versão final reapresentada em 23 de setembro de 2002 Aprovado em 8 de outubro de 2002 